\title{
Factors of Entrepreneurial Success: A qualitative multiple case study of new small businesses
}

\author{
Jan $\operatorname{Urban}^{1, *}$ \\ ${ }^{1}$ Institute of Technology and Business in České Budějovice
}

\begin{abstract}
In most countries, small businesses represent a majority of firms providing close to fifty percent of the total employment. However, on average, more than half of new small-business start-ups usually fail within the first 5 years of operation. Therefore, learning from the success of small-business owners who have sustained in business for at least 5 years can provide helpful insights not only for individual firms, but also for the continued growth of local economies which usually rely on small business to a great extent. The purpose of this case study based article was to explore common approaches, strategies and skills of successful business founders/small business owner's that contribute to their sustained development. The article is based on a qualitative survey of sixteen, locally operating, small, retail and service-industry firms which, having successfully survived at least 5 years in business, continue to grow. The method of the survey covered semi structured interviews led with individual entrepreneurs and focused on identifying the crucial business as well as personal approaches and skills important for their market survival. Keywords: small business, business owner characteristics, entrepreneurial skills, leadership skills, business planning, networking, market differentiation
\end{abstract}

\section{Introduction}

Even though the definition of an entrepreneur/small-business owner varies in the literature, the prevailing understanding is that he/she is the (sole) proprietor of a firm with fewer than 500 employees (SBA, 2016). The SBA (2012) has also defined a small business as one that is independently owned and operated, organized for profit, and is not dominant in its field.

The importance of small-businesses is based on the fact that they account for a significant portion of new job creation, total employment, private sector payroll as well as innovations that fuel the economy. Furthermore, they tend to be highly important for the continued growth of local economies.

Most new businesses, however, are fragile and often fail: worldwide, in many industries, as many as $80 \%$ of new start-ups are out of business within five years (Artinger \& Powell, 2015; Cader \& Leatherman, 2011), and even less start-ups survive 10 years (Small Business

* Corresponding author: 21537@mail.vstecb.cz 
and Entrepreneurial Council, 2016). Thus, in spite of being an important vehicle of economic growth and innovation, they are also ,responsible” for a tremendous amount of job destruction.

\section{Factors of Entrepreneurial Success: Literary Research}

The higher vulnerability of small businesses to economic slow-downs, bigger firms' competition, as well as their lack of funding are usually quoted as the main factors of their "early mortality" (Osei-Assibey, Bokpin, and Twerefou, 2012). In this regard, Schiff, Hammer, and Das (2010) noted that an important factor of their undercapitalization is the failure of the small-business owners to estimate the amount of pre-tax income that the business must generate to sustain operations and profitability. Furthermore, collecting sufficient capital for expanding their operations is another crucial factor since growing to a level necessary for economic efficiency (Salazar, Soto, \& Mosqueda, 2012) is quite often is a prerequisite for small-businesses market survival.

Cronin-Gilmore (2012) suggested that while small-business owners have usually good knowledge of their product or service, they typically lack skills to develop a strategic and operational business plans. Eddleston, Kellermanns, Floyd, Crittenden, and Crittenden (2013) noted business owners who developed and updated the strategic business plans experienced fewer failures than other small-businesses. Even for initially successful firms, the challenges may include how to develop innovation strategies to sustain long-term growth (Adams, Kauffman, Khoja, \& Coy, 2016).

Similarly, creating effective marketing plans, determining what to offer and to whom, can be challenge for a small-business owner (Perry, 2014). As Box (2011) concluded, the new businesses owners may have to adopt aggressive „guerrilla“ marketing techniques and/or create a niche market. Communication strategies are also important in this regard; and small-business owners are increasingly using cost effective social media as a platform for their marketing, advertising, and recruitment activities (Schaupp \& Bélanger, 2014).

Last but not least, as Fahed-Sreih and Morin-Delerm (2012) stressed, a lack of leadership skills contributes to small-business owners' failures in producing efficient organizations (Sakiru, D'Silva, Othman, DaudSilong, \& Busayo, 2013) with motivated and loyal employees.

In this regard, Hansen, Shrader, and Monllor (2011) suggested that personal characteristics of small-business owners often include a strong product focus as well as focus of internal control and the need for achievement. Successful small-business owners, however, typically have to have also a leadership charisma and passion, contagious to their employees (Kao, Pai, Lin, \& Zhong, 2015). As for their people management skills, they claim, their goal alignment and delegation skill is crucial.

Simiralry, Byrd (2010) identified that the leadership practices of successful and unsuccessful small-business owners differed significantly. More precisely, according to Surdez-Pérez, Aguilar-Morales, Sandoval-Caraveo, López-Parra, \& Corral-Coronado, 2014), personal traits contributing to small business sustainability and growth include (a) strong negotiation skills, (b) creativity, (c) hard work, and (d) self-discipline. To achieve higher employee productivity and creativity, entrepreneurs should create an atmosphere that incorporates shared values, feeling of uniqueness and even play (Kauanui, Thomas, Sherman, Waters, and Gilea, 2010).

Furthermore, Insead (2011) identified social networking, interpersonal ties, and the ability to create new connections as essential characteristics of sustainability of a business. 
O'Donnell (2014) noted that networking is critical to knowledge exchange, and an increase in small-business owners' knowledge led to a higher sustainability rate in their business operations. Fifty percent of small-business owners identified their business venture came from ideas from networking contacts and/or innovations, slight variations, or creativity from existing business (Martinez \& Aldrich, 2011). Most small-business owners lack experience, do not have a history of previous success, and need funding information so networking can be of value (Martinez \& Aldrich, 2011).

\section{Methods and Data}

The purpose of this qualitatively oriented, multiple-case study was to follow the above mentioned line of research and explore the skills, knowledge, and strategies small-business owners use to succeed in business. The primary research question, guiding the study, was "What skills, knowledge, and strategies characterize small-business owners who succeed in business beyond 5 years?". In identifying these skills, stress was put on common personal features and views of entrepreneurs operating in a particular industry.

\subsection{Selection of Survey Participants}

For the purpose of the study, the definition of an entrepreneur/small-business owner was a person who began a privately owned small business, took on financial risks in seeking profits, and employs not more than 50 employees (Lawrence, 2014).

The sample comprised 16 small business owners residing in Central Bohemia and operating small retail shops and personal services outlets who sustained their business beyond 5 years, employed 10 to 50 employees and led a growing and viable/profitable business entity.

\subsection{Methods Used}

Face-to-face semi structured interviews as well as the basic financial business records provided the data for answering the research question. Data saturation occurred when no new or relevant themes or supporting information emerged during the data collection process (methodology suggested by Denzin \& Lincoln, 2011; Walker, 2012). An audio recording of the interviews was to ensure accuracy. Scheduling of the face-to-face semi structured interviews occurred at times the participants selected.

The appropriateness of the qualitative methodology used to conduct the study leans on Denzin and Lincoln conclusions (2011), that qualitative method is appropriate when (a) the problem requires more than a yes or no hypothesis, (b) a large sample may not be available, and (c) common themes are expected to result from exploring the data to address the research question.

In a similar context, this methodology was used Box (2011) who conducted a qualitative case study included small business owners and entrepreneurs in which business owners were divided into three categories - differentiators, cost leaders, or stuck in the middle when sustaining a business.

Furthermore, a case study of this kind is an adaptable approach for analysing societal and developmental disciplines (Yin, 2014).

Yin noted that the case study can be a single case or multiple cases bounded by time and location. For this study, a multiple-case study approach was used, as obtaining information from more than a single participant provided additional insights, understanding, and 
assurance of validity in identifying strategies small-business owners use to increase success rates (Denzin \& Lincoln, 2011).

\section{Results}

The success of a newly established company is always, at least in part, a matter of luck. As the interviewed entrepreneurs admitted, it depends on factors that entrepreneurs do not have complete control over.

Nevertheless, there are certain strategies, traits and ways of acting, by which successful founders, according to interviews results differ. They can be summarized in the following themes that emerged from the collected data. These themes enrich, to a great extent, earlier studies in this field, while not contradicting them, and can thus be regarded as an original study of factors contributing to an entrepreneurial success, especially in early stages of business development.

\section{Successful entrepreneurs}

- don't necessarily adhere to what competitors are doing, and are not worried about seemingly "crazy" ideas or thoughts.

While many new entrepreneurs are strongly influenced in their decisions by what their competitors do (sometimes even tend to imitate them and believe that if they follow their example, they will succeed), the members of the survey were convinced a simple recipe that companies should take over or imitate does not exist, i.e. that successful new business owners learn from the experiences of others, but „not too much.“ They understand that if all firms in a given industry took over the best and successful experiences of others, these experiences - as well as the companies that imitated them - would only become mediocre: a company that only adheres to or even takes over the procedures of others can never overrun its competitors, even if the methods themselves were successful.

The tendency not to refrain from strange-looking or even seemingly "strange" business ideas can be regarded as one of the main features of successful business founders. What seems like an almost crazy idea to others is, for them and often in fact, more of a sign that they are on the right track.

- are not afraid of markets regarded as "mature" or already occupied. Even though conventional thinking often claims that a newly founded company should locate a place in the market that is not yet fully occupied, and this strategic approach is often successful "occupied" markets can still offer opportunities, and thus do not necessarily have always have to be avoided.

The reason why even apparently mature and saturated markets often offer for innovative companies interesting opportunities. is that a new company can almost always find a field in which it can do better, such as building friendlier, more personal or otherwise better relations with its clients.

- in forming their marketing strategy, they rely on their personal experience. They even quite often trust their own first-hand experience more than various would-be professional marketing researches and market surveys Also, they are interested in what both their current or potential clients desire or complain about, and use information they gain from everyday personal contacts with people. 
- understand the importance of leadership skills and surrounding themselves with a motivated team. They understand that even a promising and interesting idea as such is, in most cases, not sufficient to develop a new business. It needs a successful implementation, and for this, the company's founders need a team.

The prerequisite is to find people who are interested in the business idea and able to contribute or help with its implementation, but also people who are "team players". Simultaneously, successful entrepreneurs do not fear to delegate gradually at least some decision-making competencies to their team. They do not mind if others decide on certain aspects of their idea or company. They trust the people around them enough and even though they sometimes cultivate a certain "cult of personality" within their company, they understand that unwillingness to delegate leads usually to stopping growth of the firm and inability to motivate or even retain important employees.

- they tackle the problems of their clients and understand the pitfalls of certain innovations. In the age of digitization, many products are becoming more customer friendly and/or easier to use. Sometimes, however, or for some customers, new products may become more complicated. And often unnecessarily.

Successful entrepreneurs or company founders are aware of these pitfalls and try to solve their problems for their customers, not to assign new ones. They allow them to orient themselves better in the "digitization jungle".

- understand they have to invest not only money but also time. Many advisors give guidance on how to better reconcile the requirements of work and personal life. This is important if we want to avoid burnout. At the same time, however, it must be understood that this is not the case for the founders of successful companies, at least in the first years.

People who start thinking at the end of the weekend about when to take their next vacation are not the most suitable for business. Even those who feel guilty about their time at work and not with their family are not entirely suitable for them. It may not and should not always be the case, but the initial stages of business require time from the founder.

- do not always try to keep their new business ideas secret. Sometimes a newly established company may not be able to complete a new product or concept completely. In that case, it will usually do better if it publishes it or even introduces it to the market as unfinished, and only tries to complete it afterwards, even in cooperation with other companies.

Thus, an interesting business idea does not always have to be kept secret, contrary to ordinary views. Sometimes it may be more appropriate to share it with others and work it out or finalize it with them. If a newly established company tries to present its product only in a definitive and perfect form, it will often find out at the moment of its launch that other companies have already entered it with a similar idea. By negotiating with potential partners, this danger can be avoided.

- use various forms of professional external support. Successful company founders are no longer mostly "lone fighters". They use all forms of support that are offered to them and do not resist them. It can be the support of the state and economic or business associations, but also help from schools and their professional or research background. 
The goal of this support can be not only the development of a new product, but also the acquisition of managerial know-how, which the founders of companies do not always have at their disposal. It can also include help in solving problems with the management and leadership of people or organizations of the company, which the founders sometimes underestimate.

\section{Discussion}

Most business founders surveyed admitted that while they trusted in their business idea, they began to operate without adequate professional background. Specifically, they were lacking at least some business skills, knowledge, and strategies to succeed. Mainly, they admitted to have a very basic knowledge of accounting procedures and financial planning in the initial stages of business development, and often sought help from family and friends to learn how to become more adept in these areas.

Most participants, however, asserted that while business background is very helpful, friendliness, hospitality, and a welcoming spirit were key catalysts for achieving customer satisfaction. On top of that, most of them were convinced that not just the quality of customer service but also an interest in the community belonged to the most important ingredients in their capability to survive successfully for 5 or more years.

Some of them, in this regard, described customers as family, knowing most, if not all, regular customers by name as well as their usual order. All owners appeared to have customer relationships that perhaps a larger chain store could not achieve.

As far as people management and leadership skills, most participants mentioned that initial challenges of their business development involved a high rate of employee turnover and/or hiring the right people.

All participants noted the importance of the challenge of keeping staff motivated and happy, one of them shared that "open dialog and clear communications of expectations are critical." Another asserted that being involved on a personal level and being supportive of employees reduces turnover as the employees feel personally invested in the business. Most offered motivational rewards, some celebrated holidays with the employees. Most, however, expressed also a need to improve their interview process to make better hiring decisions and get the right fit of employees for the job as well as the culture of the business.

Several owners believed that while running an efficient business is important, it should also be fun.

When asked what the best advice they could offer to future small-business owners, the participants responded as follows: "Have a good attitude and radiate your passion and dedication to your business and the customers", "Do not offer what everyone else if offering. Set yourself apart from the crowd. Keep it local with great products and fresh quality." One should "learn from your mistakes. Just because something did not work out the first time, do not give up. Give the customer what they want and a great experience and they will return with friends."

In terms of business development, word of mouth was one of the primary sources of initial advertising for all participants. Each of the participants noted overcoming the challenge of how to attract customers after they established credibility as a legitimate business. 


\subsection{Recommendations for Further Study}

Recommendations for further research include focusing on different sizes of small business in different industries and varying geographical locations. Future researchers should also consider studying small-business owners who have increased profitability and examine the relevance of gender and age variances of the small-business owners through quantitative designs. Moreover, focusing on each of the specific themes identified within this study would provide more detailed areas for additional research.

\section{Conclusion}

The purpose of this descriptive, qualitative multiple case study was to explore what skills, knowledge, and strategies small-business owners use to succeed in business beyond 5 years. The study covered business from retail and personal service industries and the data sources included participant interview data, information concerning their financial results and observations from site visits of the businesses concerned.

The main and, as we believe, original findings of the study can be summarized in the following conclusions.

Successful entrepreneurs (a) feel the need for marketing differentiation, and don't necessarily adhere to what their competition is doing. Nor are they worried about apparently strange business concepts or ideas, (b) are not afraid of "mature" or occupied markets, (c) rely on personal information they get from daily contacts with people, both in the area of their business and outside it, (d) surround themselves with a motivated and empowered team, (e) tackle the problems of their clients, and specifically try not to come up with new ones for their clientele, (f) are not afraid to invest not only money but also time (g) do not always try to keep their new business ideas secret if the business development asks for co-operation with other subjects, (h) they do not mind using various forms of external professional support including the support of local business owners networking.

\section{References}

1. ADAMS, J., R. G. KAUFFMAN, F. M. KHOJA and S. COY, 2016. Looking at purchasing development through the lens of small business. Journal of Managerial Issues, 28(3/4), 145-170. ISSN 1045-3695.

2. ARTINGER, S. and T. C. POWELL, 2015. Entrepreneurial failure: Statistical and psychological explanations. Strategic Management Journal, 37(6), 1047-1064. ISSN 1097-0266.

3. BOX, T. M., 2011. Small firm strategy in turbulent times. Academy of Strategic Management Journal, 10(1), 115-122. ISSN 1939-6104.

4. BOX, T. M. and W. D. MILLER, 2011. Small-firm competitive strategy. Academy of Strategic Management Journal, 10(1), 55-59. ISSN 1939-6104.

5. BYRD, W., 2010. The personal leadership practices of successful entrepreneurs (Doctoral dissertation). Available from ProQuest Dissertations and Theses database. (UMI No. 3412018)

6. CADER, H. A. and J. C. LEATHERMAN, 2011. Small business survival and sample selection bias. Small Business Economics, 37(2), 155-165. ISSN 0921-898X.

7. CRONIN-GILMORE, J. 2012. Exploring marketing strategies in small businesses. Journal of Marketing Development and Competitiveness, 6(1), 96-107. ISSN 21552843. 
8. DENZIN, N. K., and Y. S. LINCOLN, 2011. The Sage handbook of qualitative research (4th ed.). Thousand Oaks, CA: Sage Publications. ISBN-13 978-1412974172.

9. EDDLESTON, K. A. et al., (2013). Planning for growth: Life stage differences in family firms. Entrepreneurship: Theory and Practice, 37(5), 1177-1202. ISSN 1042258 .

10. FAHED-SREIH, J. AND S. MORIN-DELERM, 2012. A perspective on leadership in small businesses: Is the need for achievement a motive in predicting success? International Journal of Entrepreneurship, 16(1), 1-23. ISSN: 1939-4675.

11. HANSEN, D. J., R. SHRADER and J. MONLLOR, 2011. Defragmenting definitions of entrepreneurial opportunity. Journal of Small Business Management, 49(2), 283304. ISSN 2515-1274.

12. HUNTER, M. G., 2011. Understanding the common causes of small business failures: A qualitative study. Journal of Applied Management and Entrepreneurship, 16(1), 87104. ISSN 1077-1158.

13. INSEAD, L. C., 2011. Competitors' resource-oriented strategies: Acting on competitors' resources through interventions in factor markets and political markets. Academy of Management, 33(1), 197-121. ISSN 0001-4273.

14. JACKSON, E. A. and H. F. JACKSON, 2016. The role of corporate social responsibility in improving firms' business in directions of sustainable development, accountability and transparency. Economic Insights - Trends and Challenges, 68(1), 39-50. ISSN 2284-8576.

15. KAUANUI, S. K. et al., 2010. An exploration of entrepreneurship and play. Journal of Organizational Change Management, 23(1), 51-70. ISSN 0953-4814.

16. KAO, P. et al., 2015. How transformational leadership fuels employees' service innovation behaviour. Service Industries Journal, 35(7/8), 448-466. ISSN 0264-2069.

17. LUSSIER, R. N. and C. E. HALABI, 2010. A three-country comparison of business success versus failure prediction model. Journal of Small Business Management, 48(3), 360-377. ISSN 2515-1274.

18. MARTINEZ, M. A. and H. E. ALDRICH, 2011. Networking strategies for entrepreneurs: Balancing cohesion and diversity. International Journal of Entrepreneurial Behaviour and Research, 17(1), 7-38. ISSN 1355-2554.

19. MCLARTY, R., M. PICHANIC and J. SRPOVA, 2012. Factors influencing the performance of small to medium-sized enterprises: An empirical study in the Czech Republic. International Journal of Management, 29(3), 36-47. ISSN 2277- 5846.

20. O'DONNELL, A., 2014. The contribution of networking to small firm marketing. Journal of Small Business Management, 52(1), 164-187. ISSN 2515-1274.

21. OSEI-ASSIBEY, E., G. BOKPIN, and D. TWEREFOU, 2012. Microenterprise financing preference: Testing $\mathrm{POH}$ within the context of Ghana's rural financial market. Journal of Economic Studies, 39(1), 84-105. ISSN 0144-3585.

22. PERRY, M. (2014). Market orientation in small businesses: Creative or lacking? Marketing Management Journal, 24(1), 96-107. ISSN 2333-6099.

23. SAKIRU, O. K. et al.,2013. Leadership styles and job satisfaction among employees in small and medium enterprises. International Journal of Business and Management, 8(13), 34-41. ISSN 2321-8916.

24. SALAZAR, A. L., R. C. SOTO and R. E. MOSQUEDA, 2012. The impact of financial decisions and strategy on small business competitiveness. Global Journal of Business Research, 6(2), 93-103. ISSN 1931-0277.

25. SCHAUPP, L. and F. BÉLANGER, 2014. The value of social media for small businesses. Journal of Information Systems, 28(1), 187-207. ISSN 0306-4379.

26. SCHIFF, A., S. HAMMER and M. DAS, 2010. A financial feasibility test for aspiring entrepreneurs. Entrepreneurial Executive, 15(3), 33-38. ISSN 1087-8955. 
27. SENGE, P. M. et al., 2010. The necessary revolution: How individuals and organizations are working together to create a sustainable world. New York, NY: Doubleday. ISBN 978-0-385-51904-5.

28. Small Business and Entrepreneurial Council. (2016). Small business facts and data. Retrieved from http://sbecouncil.org/about-us/facts-and-data/

29. Surdez-Pérez, E. et al., 2014. The relationship between company performance and owner characteristics: Evidence from Mexico. Global Journal of Business Research, 8(2), 13-22. ISSN 1931-0277.

30. U.S. Small Business Administration (SBA). (2012). Growing your business. Retrieved from http://www.sba.gov/content/ideas-growing-your-business

31. U.S. Small Business Administration (SBA). (2016). Frequently asked questions. Retrieved from https://www.sba.gov/sites/default/files/advocacy/SB-FAQ2016_WEB.pdf

32. YIN, R. K., 2014. Case study research: Design and methods, (5th ed.). Thousand Oaks, CA: Sage Publications. ISBN 978-1-4522-4256-9. 